Revista Brasileira de Agricultura Irrigada v.7, nº. 2, p. 170 - 180, 2013

ISSN 1982-7679 (On-line)

Fortaleza, CE, INOVAGRI - http://www.inovagri.org.br

DOI: $10.7127 /$ rbai.v7n200011

Protocolo 011.13 - 06/03/2013 Aprovado em 02/05/2013

\title{
CLASSIFICAÇÃO CLIMÁTICA E ZONEAMENTO AGROCLIMÁTICO PARA O MUNICÍPIO DE AMARANTE - PI
}

\author{
Raimundo Mainar de Medeiros ${ }^{1}$; Pedro Vieira de Azevedo ${ }^{2}$; \\ Luciano Marcelo Falle Saboya ${ }^{3}$; Paulo Roberto Megna Francisco ${ }^{4}$
}

\begin{abstract}
RESUMO
Utilizando-se as séries temporais mensais de precipitação pluviométrica e temperatura do ar, elaborou-se a classificação climática e o zoneamento agroclimático para as principais culturas exploradas no município de Amarante-PI, como resposta a necessidade de se conhecer aquelas mais adequadas a semeadura na região. $\mathrm{O}$ método adotado para obtenção do balanço hídrico climático foi o proposto por Thornthwaite \& Mather. Verificou-se que o período chuvoso se concentra entre os meses de dezembro a abril; a deficiência hídrica no município ocorre no período de junho a dezembro; a maior disponibilidade hídrica ocorre no período de janeiro a maio; a evapotranspiração potencial é mínima no mês de fevereiro e máxima no mês de outubro, ao passo que a evaporação real concentra os picos de mínima e máxima nos meses de agosto e dezembro, respectivamente. A média da temperatura mensal mostrou-se máxima em setembro e mínima em fevereiro; o índice de umidade é de 15,61\%, o de aridez é de $45,92 \%$ e o hídrico de $-30,30 \%$. Considerando no balanço hídrico climatológico e no evapopluviograma, observou-se condições de aptidão plena para as culturas da cana-deaçúcar, feijão, milho, banana, caju; de aptidão moderada para as culturas de: banana, caju, feijão, abacaxi e de inapto para a cultura do algodão herbáceo.
\end{abstract}

Palavras-chave: Climatologia, Balanço hídrico climático, Evapopluviograma.

\begin{abstract}
Using the time series of monthly precipitation and air temperature, elaborated the classification climate and agroclimatic zoning for the main crops grown in the municipality of Amarante-PI, as a response to the need to meet those most suitable sowing in the region. The method used for obtaining the water balance was proposed by Thornthwaite \& Mather. It was found that the rainy season is concentrated between the months from December to April, the water deficit in the municipality occurs in the period from June to December, the highest soil

\footnotetext{
${ }^{1}$ Meteorologista, Doutorando em Meteorologia, PPGM, UFCG, Campina Grande-PB, Av. Aprígio Nepomuceno, 882, CEP 58109-970, Fone: (83) 2101-1000, Email: mainarmedeiros@ gmail.com

${ }^{2}$ Prof. Dr. do CTRN, DCA, UFCG, Campina Grande - PB, Brasil, CEP. 58109-970. Email: pedroveira@dca.ufcg.edu.br

${ }^{3}$ Prof. da UFCG, Doutorando em Engenharia Agrícola, PPGEA, UFCG, Campina Grande-PB, Av. Aprígio Nepomuceno, 882, CEP 58109-970, Fone: (83) 2101-1000, Email: saboya@ deag.ufcg.edu.br

${ }^{4}$ Dr. Engenharia Agrícola, Instituto Penha e Margarida de Desenvolvimento Socioeconômico e Cultural, Alagoa Grande-PB, Rua Dr. Francisco Montenegro, s/n, CEP 58388-000, Email: paulomegna @ig.com.br
} 


\section{CLASSIFICAÇÃO CLIMÁTICA E ZONEAMENTO AGROCLIMÁTICO PARA O MUNICÍPIO DE AMARANTE - PI}

water occurs in the period from January to May; potential evapotranspiration is minimal in the month of February and maximum in October, while the actual evaporation concentrates the minimum and maximum peaks in the months of August and December, respectively. The average monthly temperature was found to be maximum in September and minimum in February, the moisture content is $15.61 \%$, the aridity is $45.92 \%$ and $-30.30 \%$ for water. Considering the climatic water balance and evapopluviograma, observed conditions of full fitness for crops of sugar cane, beans, corn, banana, cashew, moderate suitability for crops: banana, cashews, beans, pineapple and of unfit for the cultivation of upland cotton. Keyword: Climatology, Climatic water balance, Evapopluviogram.

\section{INTRODUÇÃO}

As áreas de delimitação do clima de um determinado município numa determinada região permitem não só estabelecer os indicadores do potencial do meio físico para a região, mas também limitar as áreas homogêneas sob o ponto de vista socioeconômico contribuindo para o planejamento e desenvolvimento sustentável.

A água é fundamental para o desenvolvimento das culturas, a sua falta ou excesso pode influenciar na produção agrícola de determinada localidade ou de uma região. A técnica do balanço hídrico fornece o saldo de água disponível no solo para o vegetal, ou seja, contabiliza a entrada (precipitação e ou irrigação) e a saída (evapotranspiração potencial), considerando determinada capacidade de armazenamento de água pelo solo (Medeiros, 2007)

A delimitação do clima de uma região permite estabelecer os indicadores do potencial do meio físico para o local em estudo, bem como as delimitações das áreas homogêneas, do ponto de vista socioeconômico, contribuiu para o planejamento e desenvolvimento sustentável da região. Desta forma, o zoneamento agroclimático constitui-se numa ferramenta importante no processo de tomada de decisão, permitindo, a partir das análises das variabilidades climáticas locais e de sua espacialização, a delimitação de regiões com diferentes aptidões climáticas aos cultivos. A definição de épocas de semeaduras ajustadas, associadas a estudos

probabilísticos da distribuição temporal das chuvas, bem como a recomendação de cultivares com maiores potenciais produtivos, maior resistência ao déficit hídrico e com ciclos mais precoces, podem diminuir os efeitos causados pela má distribuição das chuvas e pelo uso de tecnologias não adequadas à região (Assad, 1994).

Rolim et AL, 2007 utilizou-se da classificação de Köpper e de Thornthwaite para a determinações das zonas agrícolas para o Estado de São Paulo.

Medeiros et al, 2011 mostrou uma caracterização e classificação climática do município de Campina Grande-PB para a produção da cultura da mandioca entre os meses de março e junho e mostrou também que a umidade e o calor são essenciais para a brotação e enraizamentos da mandioca.

Francisco et al, 2011, apresentou um mapeamento das potencialidades climáticas e edificas para o município de Picuí - PB, visando à exploração racional, seu desenvolvimento sustentável e econômico, com base nas aptidões de solo, clima e as recomendações da portaria do Ministério da Agricultura e Reforma Agrária.

O programa de zoneamento agrícola do Ministério da Agricultura, Pecuária e Abastecimento (MAPA), que teve início no Brasil em 1996, tem se constituído num instrumento de apoio à 


\section{CLASSIFICAÇÃO CLIMÁTICA E ZONEAMENTO AGROCLIMÁTICO PARA O MUNICÍPIO DE AMARANTE - PI}

política agrícola do Governo Federal na área de crédito e segurança rural, bem como instrumento de indução ao uso de tecnologias e de suporte para a tomada de decisão no programa de garantia da atividade agropecuária (PROAGRO), além de servir de referencial para as empresas privadas que atuam na área securitária no Brasil (Cunha \& Assad, 2001).

As culturas e as áreas nas quais se adéquam às condições climáticas $(\mathrm{CC}) \mathrm{em}$ Amarante-PI podem promover $\mathrm{O}$ desenvolvimento de uma agricultura produtiva, rentável e socioeconomicamente viável aos produtores, tendo como base o zoneamento agrícola realizado para a região. Segundo Assad (1994), qualquer

\section{MATERIAIS E MÉTODOS}

O município de Amarante localizado na microrregião do Médio Parnaíba Piauiense, com uma área de $1.150,0 \mathrm{~km}^{2}$ distante da capital $126 \mathrm{~km}$, com latitude $06^{\circ} 14^{\prime} 36^{\prime}$ 'Sul e longitude 42 $51^{\prime} 24^{\prime}$ 'Oeste e altitude de 72 metros estudo sobre zoneamento agrícola busca delimitar áreas que tenham potencial produtivo e que mantenham essas potencialidades ao longo do tempo, com um mínimo de impactos ao meio ambiente. Esses estudos permitem, além da definição das melhores datas de plantio e ou semeadura, aprofundar a delimitação de zonas pluviometricamente homogêneas.

Este trabalho objetiva, com base nos resultados do balanço hídrico climatológico (BHC) e no evapopluviograma correspondente, a classificação climática e o zoneamento agroclimático (ZA) para as culturas com aptidão plena e moderada, mais adequadas à semeadura no município de Amarante-PI.

acima do nível do mar tendo como limites os municípios de Palmeirais e Angical do Piauí ao norte, ao sul Floriano e Francisco Ayres, a leste Angical, Regeneração e Arraial, e a oeste o estado do Maranhão (Figura 1).

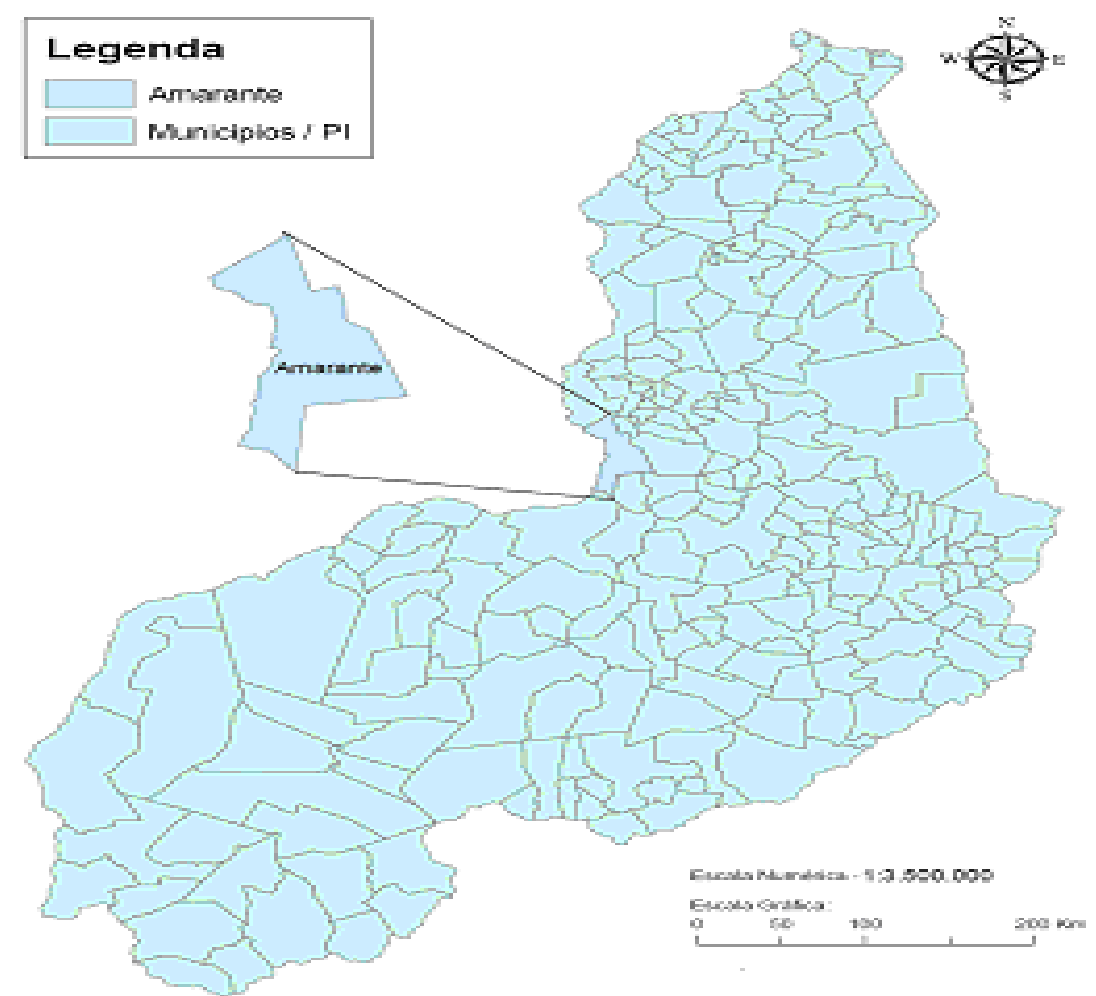

Figura 1. Localização da área de estudo. 


\section{CLASSIFICAÇÃO CLIMÁTICA E ZONEAMENTO AGROCLIMÁTICO PARA O MUNICÍPIO DE AMARANTE - PI}

Geologicamente, a área municipal está ocupada por coberturas sedimentares. Em aproximadamente $15 \%$ da área ocorre a Formação Sardinha, reunindo as litologias basalto e gabro. No restante da área afloram rochas pertencentes às unidades descritas em seguida. Os principais cursos d'água que drenam o município são os rios Parnaíba, Canindé e Mulato, além dos riachos Jacaré e Riachão (CPRM, 2004) (Figura 2).

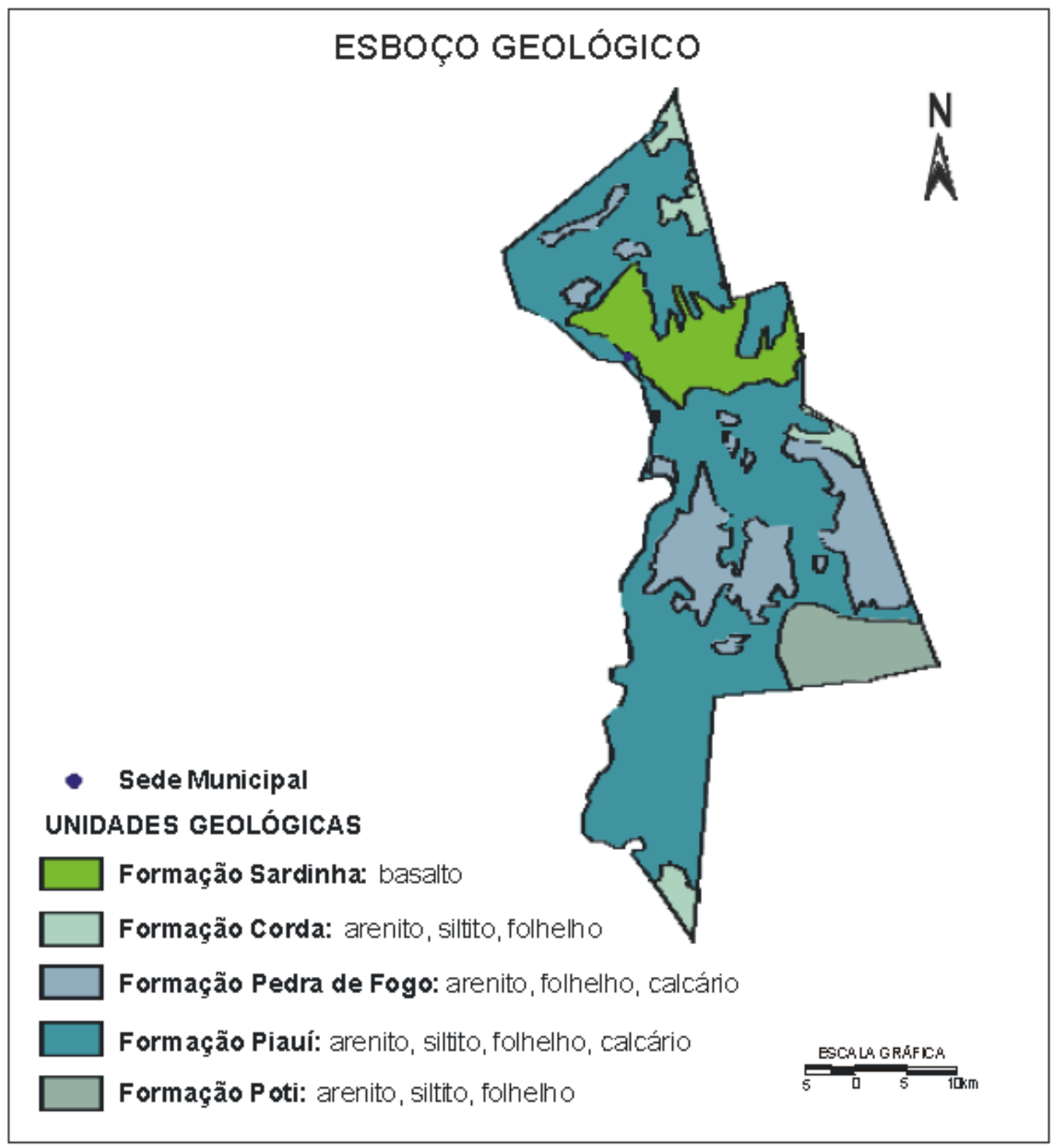

Figura 2. Esboço geológico da área de estudo. Fonte: CPRM, 2004

Os solos da região são provenientes da alteração de arenitos, basalto, gabro, folhelho, siltito, silexito e calcário. Compreendem solos litólicos, álicos e distróficos, de textura média, pouco desenvolvido, raso a muito rasos, fase pedregosa, com floresta caducifólia e/ou floresta subcaducifólia/cerrado. Associados a estes, ocorrem solos podzólicos vermelho-amarelos, textura média a argilosa, fase pedregosa e não pedregosa com misturas e transições vegetais de floresta subcaducifólia/caatinga. Secundariamente, ocorrem areias quartzosas, que compreendem solos arenosos essencialmente quartzosos, 


\section{CLASSIFICAÇÃO CLIMÁTICA E ZONEAMENTO AGROCLIMÁTICO PARA O MUNICÍPIO DE AMARANTE - PI}

profundos, drenados, desprovidos de minerais primários, de baixa fertilidade, com transições vegetais, fase caatinga hiperxerófila e/ou cerrado subcaducifólia/floresta subcaducifólia (Jacomine et al.,1986; CPRM, 2004).

As formas de relevo da região compreendem, principalmente, superfícies tabulares reelaboradas (chapadas baixas), relevo plano com partes suavemente onduladas e altitudes variando de 150 a 300 metros, superfícies tabulares cimeiras (chapadas altas), com relevo plano, altitudes entre 400 a 500 metros, com grandes mesas recortadas e superfícies onduladas com relevo movimentado, encostas e prolongamentos residuais de chapadas, desníveis e encostas mais acentuadas de vales, elevações (serras, morros e colinas), com altitudes entre 150 a 500 metros. Sequência de platôs e chapadas de altitudes médias de 400 a 600 metros acima do nível do mar, podendo alcançar 800 metros (Jacomine et al.,1986; CPRM, 2004).

Os recursos hídricos superficiais no estado do Piauí estão representados pela bacia hidrográfica do rio Parnaíba, a mais extensa dentre as 25 bacias da Vertente Nordeste, ocupando uma área de 330.285 $\mathrm{km}^{2}$, e abrange o estado do Piauí e parte dos estados do Maranhão e do Ceará. O rio Parnaíba possui 1.400 quilômetros de extensão e a maioria dos afluentes localizados a jusante de Teresina são perenes e supridos por águas pluviais e subterrâneas. Apesar do estado do Piauí estar inserido no "Polígono das Secas", não possui grande quantidade de açudes.

A região tem um regime de precipitação do setor Central do Estado com ocorrência de chuvas de pré-estação nos meses de novembro e dezembro, tendo como trimestre mais chuvoso os meses de

$$
i_{j}=\left(\overline{\frac{T_{j}}{5}}\right)^{1,514}
$$

janeiro, fevereiro e março. Apresenta temperaturas mínimas de $18{ }^{\circ} \mathrm{C}$ e máximas de $29{ }^{\circ} \mathrm{C}$ e um clima quente tropical. A precipitação pluviométrica média anual (1.174,7 mm, na sede do município) é definida no Regime Equatorial Continental, com isoietas anuais entre 800 a $1.200 \mathrm{~mm}$, com 5 a 6 meses mais chuvosos e período restante do ano de estação seca (CPRM, 2004; (Medeiros, 2007)

$\mathrm{Na}$ metodologia utilizada realizouse o balanço hídrico climático com os dados de precipitação obtidos pela Empresa de Assistência Técnica e Extensão Rural do Piauí (EMATERPI), do período de agosto de 1912 a outubro de 2010, totalizando 99 anos de precipitações diárias e mensais observadas (Medeiros, 2007, enquanto que a temperatura média foi obtida do Estudo Agrometeorológico para o Estado do Piauí (Medeiros, 2007), considerando-se apenas as médias mensais de temperatura e precipitação).

O método adotado para obtenção do balanço hídrico climático foi o mesmo proposto por Thornthwaite \& Mather (1955). Esse método contabiliza a água do solo, considerando que a precipitação representa o ganho e a evapotranspiração a perda de umidade do solo, podendo-se estimar os valores correspondentes ao excedente hídrico (EXC), evapotranspiração real (ETR) e deficiência hídrica (DEF).

A evapotranspiração potencial média mensal foi calculada em função da temperatura média do ar e da duração efetiva do dia (insolação máxima teoricamente possível). O método estabelece um índice mensal de calor obtido pela expressão: 


\section{CLASSIFICAÇÃO CLIMÁTICA E ZONEAMENTO AGROCLIMÁTICO PARA O MUNICÍPIO DE AMARANTE - PI}

onde $i_{j}$ e $\bar{T}_{j}$ são, respectivamente, o índice térmico e a temperatura média do mês j. O índice anual de calor é dado

$$
I=\sum_{j=1}^{12} i_{j}
$$

A evapotranspiração potencial em pelo somatório de $\mathrm{i}_{\mathrm{j}}(\mathrm{j}=1,2, \ldots, 12)$ ou seja:

$$
\left(E T_{p}\right)_{j}=0,533 \cdot F_{j}\left(\frac{10 . \overline{T_{j}}}{I}\right)^{a}
$$

mm/mês é calculada pela expressão:

Onde: $\quad(E T p)_{j}$ é a evapotranspiração potencial do mês j e $F_{j}$ é um fator de

$$
\mathrm{F}_{\mathrm{j}}=\mathrm{D}_{\mathrm{j}} \mathrm{N}_{\mathrm{j}} / 12
$$

Em que: $\mathrm{D}_{\mathrm{j}}$ é o número de dias do mês $\mathrm{j}$ e $\mathrm{N}_{\mathrm{j}}=2 \operatorname{arc} \cdot \operatorname{Cos}(-\operatorname{tg} \phi \operatorname{tg} \delta) / 15$ é a duração efetiva do dia 15 do mês j. $\phi$ é a latitude local e $\delta=23,45^{\circ}$ sen [360(284+d)/365], onde d é o número correção (Tabela 1) dado por:

$$
a=6,75 \times 10^{-7} I^{3}-7,71 \times 10^{-5} I^{2}+1,79 \times 10^{-2} I+0,49
$$

Tabela 1. Fator de Correção $F_{j}$ do método de Thornthwaite

Fator de correção

\begin{tabular}{cccccccccccc}
\hline Jan & Fev & Mar & Abr & Mai & Jun & Jul & Ago & Set & Out & Nov & Dez \\
1,80 & 0,97 & 1,05 & 0,99 & 1,01 & 0,96 & 1,00 & 1,01 & 1,00 & 1,06 & 1,05 & 1,10 \\
\hline
\end{tabular}

Fonte: (BRUTSAERT, 1982).

A classificação climática foi realizada segundo o método proposto por Thornthwaite, citado em Ometto (1981), utilizando os dados do balanço hídrico para a média do período estudado. O modelo de
Thornthwaite (1955) baseia-se nos resultados dos cálculos do índice de umidade $\left(\mathrm{I}_{\mathrm{u}}=100 * \mathrm{EXC} / \mathrm{ETp}\right)$; índice de aridez $\left(I_{a}=100 * D E F / E T p\right)$ e índice hídrico $\left(I_{h}=I_{u}-0,6 I_{a}\right)($ Tabela 2). 


\section{CLASSIFICAÇÃO CLIMÁTICA E ZONEAMENTO AGROCLIMÁTICO PARA O MUNICÍPIO DE AMARANTE - PI}

Tabela 2. Síntese da aptidão climática de algumas culturas

\begin{tabular}{|c|c|c|c|}
\hline CULTURA & APTIDÃO & ÍNDICE CLIMÁTICO & DEFICIÊNCIA/EXCESSO \\
\hline \multirow{6}{*}{ ABACAXI } & Plena & $\rightarrow-20 \leq \mathrm{I}_{\mathrm{h}}<20$ & \multirow{6}{*}{$\begin{array}{l}\Rightarrow \text { Boas condições hídricas e térmicas para o da cultura. } \\
\Rightarrow \text { Umidade excessiva, prejudicando o desenvolvimento } \\
\text { vegetativo e a frutificação da cultura. } \\
\Rightarrow \text { Restrições hídricas para o desenvolvimento da cultura. } \\
\Rightarrow \text { Limitações para o cultivo do abacaxi, por deficiência hídrica } \\
\text { acentuada. } \\
\Rightarrow \text { Deficiência hídrica severa, não possibilitando o } \\
\text { desenvolvimento da cultura, a não ser através de irrigação. }\end{array}$} \\
\hline & Moderada & $\rightarrow \mathrm{I}_{\mathrm{h}}>20$ & \\
\hline & & & \\
\hline & Restrita & $\rightarrow-20 \leq 1_{h}<-20$ & \\
\hline & & $\rightarrow-40 \leq \mathrm{I}_{\mathrm{h}}<-30$ & \\
\hline & Inaptidão & $\rightarrow \mathrm{I}_{\mathrm{h}}<-40$ & \\
\hline \multirow{6}{*}{$\begin{array}{l}\text { ALGODÃO } \\
\text { HERBÁCEO }\end{array}$} & Plena & & \multirow{6}{*}{$\begin{array}{l}\Rightarrow \text { Boas condições hídricas e térmicas para o desenvolvimento } \\
\text { da cultura. } \\
\Rightarrow \text { Período vegetativo normal, mas com ocorrência de seca. } \\
\Rightarrow \text { Repouso por seca insuficiente para a maturação da fibra. } \\
\Rightarrow \text { Período vegetativo curto com ocorrência de seca no mesmo. } \\
\Rightarrow \text { Umidade excessiva para o desenvolvimento da cultura. } \\
\Rightarrow \text { Ocorrência de seca durante todo o ciclo da cultura. }\end{array}$} \\
\hline & Moderada & $\rightarrow 30<\mathrm{I}_{\mathrm{v}}<50 \mathrm{I}_{\mathrm{sv}} \leq 1 ; \mathrm{I}_{\mathrm{rs}} \geq 4$ & \\
\hline & Moderada & $\rightarrow 30<\mathrm{I}_{\mathrm{v}}<50 \mathrm{I}_{\mathrm{sv}}>1 ; \mathrm{I}_{\mathrm{rs}} \geq 4$ & \\
\hline & Restrita & $\rightarrow 30<\mathrm{I}_{\mathrm{v}}<50 \mathrm{I}_{\mathrm{sv}} \leq 1 ; \mathrm{I}_{\mathrm{rs}}<4$ & \\
\hline & Restita & $\rightarrow 20<\mathrm{I}_{\mathrm{v}}<30 \mathrm{I}_{\mathrm{sv}}>1 ; \mathrm{I}_{\mathrm{v}}>50$ & \\
\hline & Inaptidão & & \\
\hline \multirow{5}{*}{ BANANA } & Plena & & \multirow{5}{*}{$\begin{array}{l}\Rightarrow \text { Boas condições hídricas para o desenvolvimento da cultura. } \\
\Rightarrow \text { Insuficiência hídrica estacional, prolongando o ciclo da } \\
\text { cultura. } \\
\Rightarrow \text { Deficiência hídrica acentuada, sendo possível o cultivo } \\
\text { apenas em várzeas e locais mais úmidos. } \\
\Rightarrow \text { Deficiência hídrica muito severa. O cultivo somente possível } \\
\text { através de irrigação. }\end{array}$} \\
\hline & Moderada & $\rightarrow 200<\mathrm{D}<350 \mathrm{~m}$ & \\
\hline & & & \\
\hline & Restrita & $\rightarrow 350<\mathrm{D}<700$ & \\
\hline & Inaptidão & $\rightarrow \mathrm{D}>700 \mathrm{~m}$ & \\
\hline \multirow{4}{*}{ CAJU } & Plena & $\rightarrow \mathrm{I}_{\mathrm{h}}>-10 \mathrm{D}<100 \mathrm{~mm}$ & \multirow{4}{*}{$\begin{array}{l}\Rightarrow \text { Em geral não há limitações climáticas para a cultura, } \\
\text { principalmente nas regiões e climas quentes. } \\
\Rightarrow \text { Ocorrência normal de pequena deficiência hídrica. } \\
\Rightarrow \text { Cultivo parcial prejudicado pela deficiência hídrica. } \\
\Rightarrow \text { Deficiência hídrica severa na maioria dos solos. Cultivo } \\
\text { somente através de suprimento da água por irrigação. } \\
\Rightarrow \text { Suprimento hídrico insuficiente para a cultura. }\end{array}$} \\
\hline & Moderada & $\begin{array}{l}\rightarrow \mathrm{I}_{\mathrm{h}}<-10100<\mathrm{D}<200 \mathrm{~mm} \\
200<\mathrm{D}<700 \mathrm{~mm}\end{array}$ & \\
\hline & Restrita & $\rightarrow 700<\mathrm{D}<900 \mathrm{~mm}$ & \\
\hline & Inaptidão & $\rightarrow \mathrm{D}>700 \mathrm{~mm}$ & \\
\hline \multirow{4}{*}{$\begin{array}{l}\text { CANA-DE- } \\
\text { AÇUCAR }\end{array}$} & Plena & $\rightarrow \mathrm{Ih}>0 ; \mathrm{D}<200 \mathrm{~mm}$ & \multirow{4}{*}{$\begin{array}{l}\Rightarrow \text { Boas condições hídricas para o desenvolvimento da cultura } \\
\Rightarrow \text { Ocorrência de seca estacional; cultivo recomendado em } \\
\text { várzeas úmidas. } \\
\Rightarrow \text { Ocorrência de seca estacional intensa. Cultivo possível com } \\
\text { irrigação suplementar. } \\
\Rightarrow \text { Carência hídrica muito severa par a cultura da cana de açúcar. }\end{array}$} \\
\hline & Moderada & $\rightarrow \mathrm{I}_{\mathrm{h}}>0 ; \mathrm{D}>200 \mathrm{~mm}$ & \\
\hline & Restrita & $\rightarrow 0>\mathrm{I}_{\mathrm{h}}>-10$ & \\
\hline & Inaptidão & $\rightarrow \mathrm{I}_{\mathrm{h}}<-10$ & \\
\hline \multirow{4}{*}{ FEIJÃ̃ } & Plena & $\rightarrow \mathrm{I}_{\mathrm{v}}>301<\mathrm{I}_{\mathrm{rs}}<5$ & \multirow{4}{*}{$\begin{array}{l}\Rightarrow \text { Melhores condições climáticas para o desenvolvimento da } \\
\text { cultura. } \\
\Rightarrow \text { Período vegetativo curto. } \\
\Rightarrow \text { Aptidão plena para variedades precoces. } \\
\Rightarrow \text { Deficiência hídrica acentuada, necessitando suprimento } \\
\text { d'água por irrigação. } \\
\Rightarrow \text { Cultivo inapropriado por insuficiência hídrica acentuada. } \\
\text { Cultivo possível apenas com irrigacão. }\end{array}$} \\
\hline & Moderada & $\rightarrow 25<\mathrm{I}_{\mathrm{v}}<30$ & \\
\hline & & $\begin{array}{l}\mathrm{C}>20 \mathrm{~mm} ; \mathrm{T}_{\mathrm{a}}>22{ }^{\circ} \mathrm{C} \\
\rightarrow 2<\mathrm{I}_{\mathrm{v}}<25\end{array}$ & \\
\hline & Inaptidão & $\rightarrow \mathrm{I}_{\mathrm{v}}<20 ; \mathrm{D}>20 \mathrm{~mm}$ & \\
\hline \multirow{5}{*}{ MILHO } & Plena & $\begin{array}{l}\rightarrow 40<\mathrm{I}_{\mathrm{v}}<60 \\
\mathrm{D}>0 ; \mathrm{T}>19^{\circ} \mathrm{C}\end{array}$ & $\begin{array}{l}\Rightarrow \text { Condições hídricas e térmicas satisfatórias para o } \\
\text { desenvolvimento da cultura. }\end{array}$ \\
\hline & Moderada & $\rightarrow 30<\mathrm{I}_{\mathrm{v}}<40$ & $\Rightarrow$ Pequena insuficiência hídrica no período vegetativo, com \\
\hline & & $\mathrm{D}<0 ; \mathrm{S}<500 \mathrm{~mm}$ & $\begin{array}{l}\text { umidade excessiva na maturação. Aptidão plena para variedades } \\
\text { precoces. }\end{array}$ \\
\hline & Restrita & $\rightarrow \mathrm{I}_{\mathrm{v}}<20$ & $\begin{array}{l}\Rightarrow \text { Deficiência hídrica severa para o desenvolvimento da cultura, } \\
\text { ou insuficiência térmica. }\end{array}$ \\
\hline & Inaptidão & $\begin{array}{l}\rightarrow \mathrm{I}_{\mathrm{h}}>-10 \\
\mathrm{D}>100 \mathrm{~mm} ; \mathrm{S}<500 \mathrm{~mm}\end{array}$ & $\begin{array}{l}\Rightarrow \text { Deficiência hídrica muito severa, tornando inviável o cultivo } \\
\text { do milho. }\end{array}$ \\
\hline
\end{tabular}




\section{CLASSIFICAÇÃO CLIMÁTICA E ZONEAMENTO AGROCLIMÁTICO PARA O MUNICÍPIO DE AMARANTE - PI}

\section{RESULTADOS E DISCUSSÃO}

Para o município em estudo verificou-se uma temperatura média anual de $25,9{ }^{\circ} \mathrm{C}$, com oscilações mensais de 24,7 ${ }^{\circ} \mathrm{C}$, a mínima ocorrida no mês de fevereiro e a máxima de $29,4{ }^{\circ} \mathrm{C}$ no mês de setembro. Os dados de precipitação pluviométrica evidenciaram um total médio anual de $1.174,7 \mathrm{~mm}$, com variações entre os meses de novembro a abril de 88,9 a $281,4 \mathrm{~mm}$. O mês de março mostrou-se ser o mais chuvoso, com um total mensal de 281,4 mm. Nos meses de maio a outubro os índices pluviométricos flutuam entre 3,4 a $64,3 \mathrm{~mm}$, demonstrando que estes índices são insignificantes para a produção agrícola de sequeiro e com pouca contribuição para o armazenamento de água no solo.

$\mathrm{Na}$ análise de deficiência hídrica (Tabela 3), as variações dos índices oscilam entre $15,7 \mathrm{~mm}$ no mês de dezembro a $180,9 \mathrm{~mm}$ no mês de setembro, totalizando $847,2 \mathrm{~mm}$ anuais. Observa-se que a evapotranspiração potencial (ETp) apresentou taxa anual média de 1.845,4 $\mathrm{mm}$, com variações de $114,5 \mathrm{~mm}$ no mês de fevereiro a 205,5 $\mathrm{mm}$ no mês de outubro, observa-se que ocorre um alto índice de água evapotranspirada quando comparada a precipitação climatológica registrada. A evapotranspiração real (ETr) apresentou-se com uma flutuação mínima de 6,3 $\mathrm{mm}$ no mês de agosto e a máxima ETr que ocorre no mês de dezembro com $139,8 \mathrm{~mm}$, com uma taxa anual evapotranspirada de 998,1 $\mathrm{mm}$. Com relação ao índice de armazenamento, observou-se que nos meses de janeiro a maio têm-se as maiores taxas de armazenamento, variando entre 48,0 a $100,0 \mathrm{~mm}$. Nos meses de junho a setembro a taxa de armazenamento oscila entre 0,1 a $14,5 \mathrm{~mm}$, sendo praticamente insuficiente à contribuição agrícola e dos meses de outubro a dezembro os valores de armazenamento é zero.

Tabela 3. Cálculo do balanço hídrico climatológico (BHC) para o período de 1961 a 1990, considerando a capacidade de água disponível (CAD) de 100,0 mm.

\begin{tabular}{lrrrrrrr}
\hline \multicolumn{1}{c}{ Meses } & $\mathrm{T}\left({ }^{\circ} \mathrm{C}\right)$ & $\mathrm{P}(\mathrm{mm})$ & $\mathrm{ETp}(\mathrm{mm})$ & $\mathrm{ARM}(\mathrm{mm})$ & $\mathrm{ETr}(\mathrm{mm})$ & $\mathrm{DEF}(\mathrm{mm})$ & $\mathrm{EXC}(\mathrm{mm})$ \\
\hline Jan & 26,5 & 193,6 & 135,6 & 58,0 & 135,6 & 0,0 & 0,0 \\
Fev & 25,9 & 222,6 & 114,5 & 100,0 & 114,5 & 0,0 & 66,1 \\
Mar & 26,3 & 280,9 & 133,4 & 100,0 & 133,4 & 0,0 & 147,5 \\
Abr & 26,4 & 202,8 & 129,2 & 100,0 & 129,2 & 0,0 & 73,6 \\
Mai & 26,7 & 63,5 & 137,8 & 47,5 & 115,9 & 21,9 & 0,0 \\
Jun & 26,8 & 15,1 & 134,1 & 14,5 & 48,2 & 85,9 & 0,0 \\
Jul & 27,1 & 4,5 & 144,7 & 3,6 & 15,4 & 129,3 & 0,0 \\
Ago & 28,3 & 3,6 & 173,7 & 0,6 & 6,5 & 167,2 & 0,0 \\
Set & 29,4 & 17,8 & 198,7 & 0,1 & 18,4 & 180,4 & 0,0 \\
Out & 29,3 & 52,3 & 205,5 & 0,0 & 52,4 & 153,1 & 0,0 \\
Nov & 28,6 & 90,3 & 182,8 & 0,0 & 90,3 & 92,5 & 0,0 \\
Dez & 27,2 & 140,3 & 155,5 & 0,0 & 140,3 & 15,2 & 0,0 \\
TOTAIS & 328,5 & 1174,7 & 1845,4 & 424,4 & 1000,0 & 845,4 & 287,3 \\
MÉDIAS & 27,4 & 107,3 & 153,8 & 35,4 & 83,3 & 70,5 & 23,9 \\
\hline
\end{tabular}

Utilizou-se de quatro tipos climáticos predominantes, característicos do cenário pluviométrico: seco, regular, chuvoso e médio da área de estudo, onde a sua distribuição espacial e temporal fluem com maior intensidade. Deste modo, com os dados do balanço hídrico (Tabela 3) obtiveram-se as seguintes classificações (Tabela 4). 


\section{CLASSIFICAÇÃO CLIMÁTICA E ZONEAMENTO AGROCLIMÁTICO PARA O MUNICÍPIO DE AMARANTE - PI}

Tabela 4. Classificação climática segundo Thorntwaite \& Mather, utilizando o balanço hídrico e os índices: hídricos, aridez e umidade.

Tipos climáticos predominantes

\begin{tabular}{ccccc}
\hline Cenário pluviométrico & Seco & Regular & Chuvoso & Médio \\
Classificação & Árido & Semiárido & Subúmido & Subúmido Seco \\
\hline
\end{tabular}

Fonte: EMBRAPA Meio Norte, 2006

Deficiência, Excedente, Retirada e Reposição Hídrica ao longo do ano

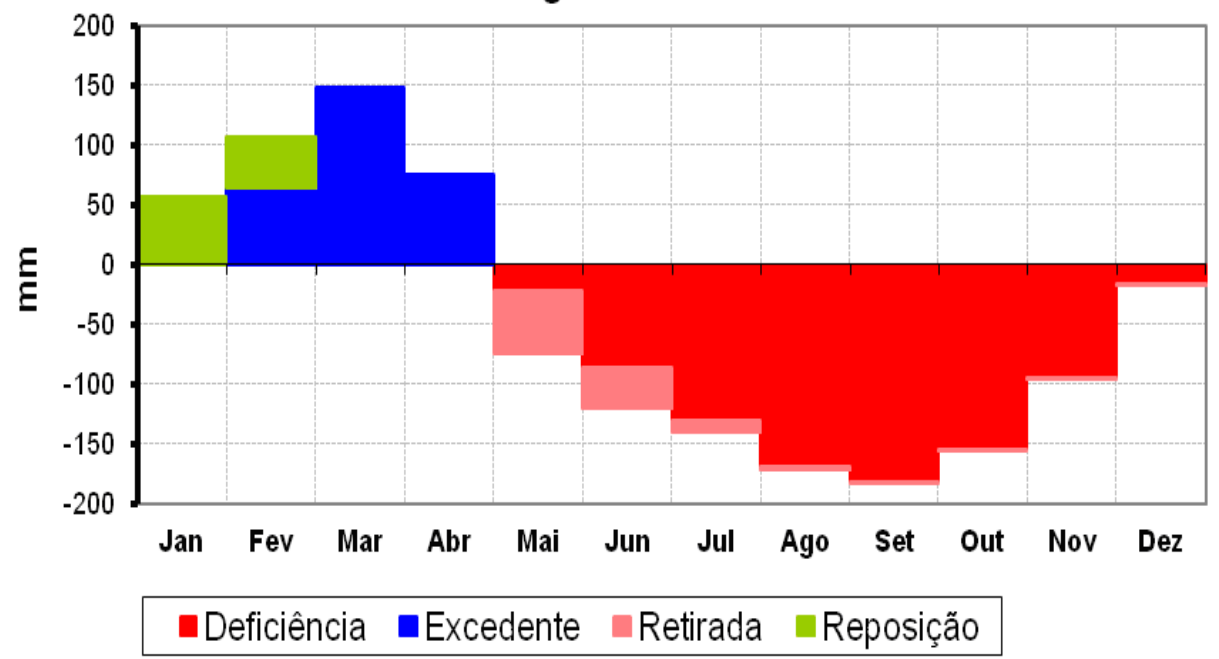

Figura 3. Balanço hídrico para o município de Amarante.

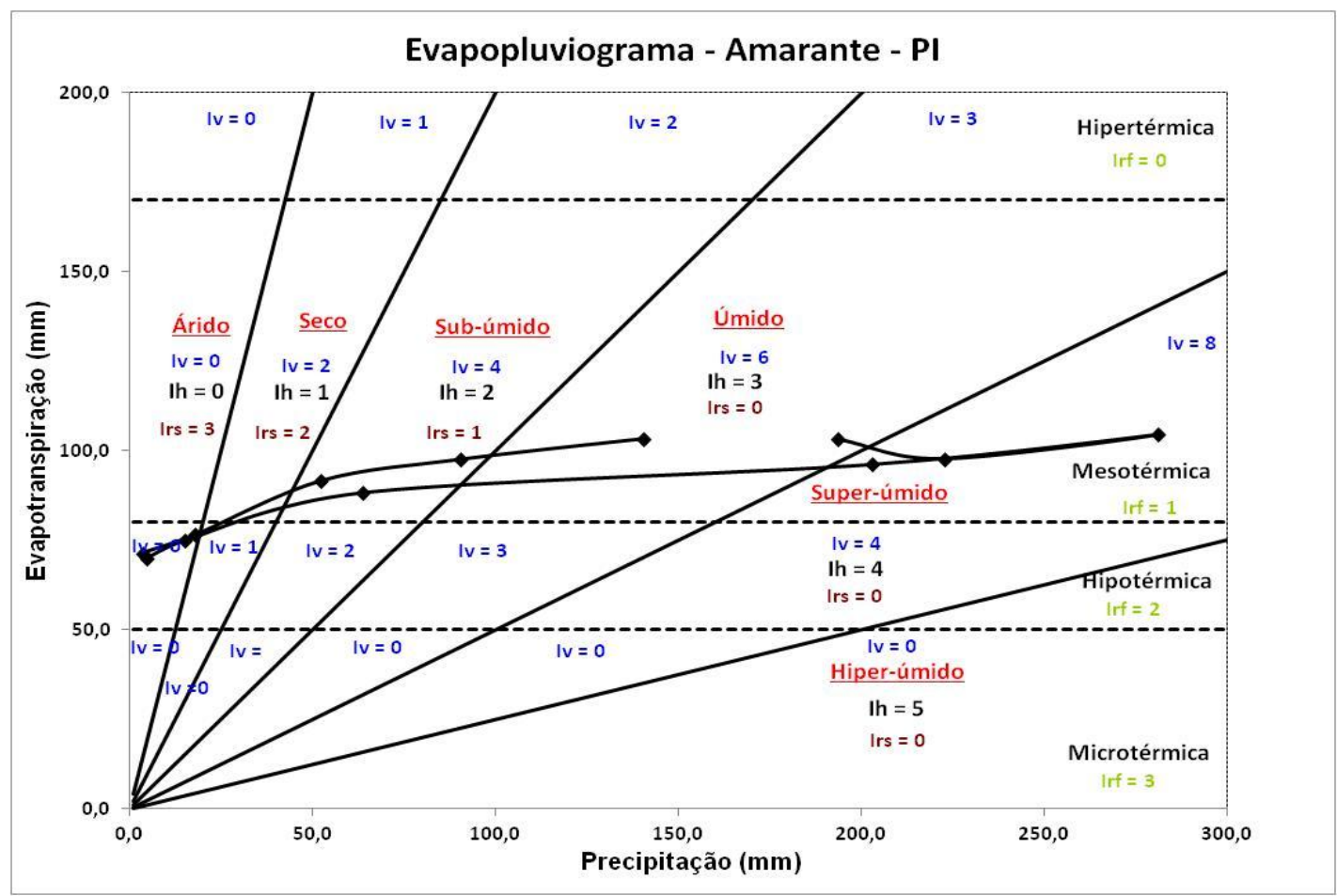

Figura 4. Evapopluviograma para o município de Amarante. 


\section{CLASSIFICAÇÃO CLIMÁTICA E ZONEAMENTO AGROCLIMÁTICO PARA O MUNICÍPIO DE AMARANTE - PI}

Com base no evapopluviograma (Figura 4) foi obtido o índice de vegetação $\left(\mathrm{I}_{\mathrm{v}}\right)$, o qual é utilizado para caracterizar as

\section{CONCLUSÕES}

Segundo a classificação de Köpper o município de Amarante - PI, tem clima tropical quente e úmido, com estação chuvosa, iniciando no verão e atingindo o máximo no outono e inverno seco.

O clima de Amarante - PI é classificado como tropical úmido-seco,com duração do período seco de seis meses, segundo Thorntwaite \& Mather.

\section{AGRADECIMENTOS}

A Capes (Coordenação de Aperfeiçoamento de Pessoal de Nível

\section{REFERÊNCIAS BIBLIOGRÁFICAS}

ADERSON JÚNIOR, S. A.; BASTO E. A.; BARROS, A. H. C.; DA SIVA, C. O.; GOMES, A. A. N. Classificação Climática do Estado do Piauí. Teresina: Embrapa Meio-Norte, 2006. 86p. Documento; 86.

ASSAD, E. D. Chuvas nos cerrados. Brasília: Embrapa Cerrados/SPI, 1994, 423p.

BRUTSAERT, W. H. (1982). Evaporation into the Atmosphere: theory, history, and applications. Dordrecht, Holland: D. Reidel.

CPRM. Serviço Geológico do Brasil. Projeto cadastro de fontes de abastecimento por água subterrânea, estado do Piauí: Diagnóstico do município de Amarante. 2004.

CUNHA, R. G.; ASSAD, E. D. Uma visão geral sobre zoneamento agrícola Brasil. aptidões das culturas apresentadas na Tabela 2.

Com base no balanço hídrico climatológico e no evapopluviograma, observou-se condições de aptidão plena para as culturas de cana-de-açúcar, feijão, milho, banana, caju; de aptidão moderada para as culturas da banana, caju, feijão, abacaxi; e de inapta para a cultura do algodão herbáceo.

Superior) pela bolsa de doutorado ao primeiro autor.

Revista Brasileira de Agrometeorologia, v. 9, n. 3, n.especial, p.377-385, 2001.

FRANCISCO, P. R. M.; PEREIRA, F. C.; MEDEIROS, R. M. e DE SÁ, T. F. F. Zoneamento de risco climático e aptidão de cultivo para o município de Picui - PB. Revista Brasileira de Geografia Física. V.05. pág. 1043-1055, 2011.

JACOMINE, P. K. T.; CAVALCANTI, A. C.; PESSOA, S. C. P.; BURGOS, N.; MELO FILHO, H. F. R.; LOPES, O. F. \& MEDEIROS, L. A. R. Levantamento exploratório-reconhecimento de solos do Estado do Piauí. Rio de Janeiro, Embrapa/SNLCS/Sudene, 1986. 782p.

MEDEIROS, R. MAINAR, BANDEIRA, M. M., FRANCISCO, P. R. M. Caracterização e classificação climática do município de Campina Grande - PB para a produção da cultura da mandioca In: IV SIC - Simpósio Internacional de Climatologia, 2011, João Pessoa/PB. IV 


\section{CLASSIFICAÇÃO CLIMÁTICA E ZONEAMENTO AGROCLIMÁTICO}

\section{PARA O MUNICÍPIO DE AMARANTE - PI}

SIC - Simpósio Internacional de Climatologia., 2011.

MEDEIROS, R. M. Estudo agrometeorológico para o estado do Piauí. 123p. 2007. Publicações avulsas.

OMETTO, J. C. Bioclimatologia Vegetal. São Paulo: Ceres, 1981. 400 p.
THORNTHWAITE, C. W.; MATHER, J. $\mathrm{R}$. The water balance. Publication in Climatology n. 8, Laboratory of Climatology, Centerton, N. J. 1955.

ROLIM, G.S. ET AL. Classificação climática de köppen e de thornthwaite e sua aplicabilidade na determinação de zonas agroclimáticas para o estado de São Paulo. Bragantia, Campinas, v.66, n.4, p.711-720, 2007. 